\title{
Burocracia, eficiência e modelos de gestão pública: um ensaio ${ }^{1}$
}

\author{
Cecília Vescovi de Aragão
}

Revista do

\section{Considerações iniciais}

O propósito deste ensaio é apresentar uma discussão recorrente no âmbito das ciências sociais, que é o relacionamento entre burocracia e eficiência. Não pretendemos esgotar o assunto, mas, tão-somente, discutir alguns pontos de vista, tendo como meta delinear que modelos de gestão pública orientam.

Assim, num primeiro segmento, apresentaremos algumas visões sobre eficiência. Posteriormente, caracterizaremos a burocracia segundo as tradições weberiana e marxista e a crítica neoliberal, discutindo, também, as questões do insulamento burocrático e do relacionamento agente-principal. Num segundo segmento, faremos o contraponto com alguns modelos de gestão pública, tais como o tradicional ou ortodoxo, o liberal e o chamado empreendedorismo estatal. A partir deste último, discutiremos o relacionamento entre burocracia e eficiência, com um exemplo extraído do gerencialismo britânico, orientador de reformas administrativas em diversos países. Para finalizar, elencaremos algumas questões recorrentes, que norteiam diversos modelos de gestão pública em sua busca por eficiência e que têm indiscutível importância no âmbito da administração pública.

\section{Cenários}

Como pano de fundo, e para melhor compreender como se inserem as discussões que ora focalizamos sobre burocracia e eficiência, elegemos alguns momentos importantes, a balizar as construções teóricas de que tratamos, de forma a situar, ainda que brevemente, o clima intelectual, econômico, político e social reinante.

Mestre em administração pública pela EBAP/FGV e especialista em políticas públicas e gestão governamental, no Ministério da Fazenda 
A discussão weberiana do início do século XX, que partiu de uma análise que remonta à história antiga, insere-se em um momento de transformações econômicas, políticas e sociais consolidadas no século XIX. Considera fundamental o movimento de constituição do Estado moderno, em que houve a concentração dos meios de violência e administração e em que o controle da administração deixa de ser pessoal para ser estatal.

A administração pública burocrática veio substituir as formas patrimonialistas de gestão e ganha importância em função da necessidade de maior previsibilidade e precisão no tratamento das questões organizacionais. Apresenta-se como reação ao nepotismo e subjetivismo, que tiveram lugar nos primeiros anos da Revolução Industrial.

A partir da década de 30 deste século, ocorre um processo de expansão do aparelho burocrático do Estado, dado o movimento de utilização do investimento público também com propósitos estabilizadores. É um momento de aumento da base fiscal e tributária, garantindo os recursos necessários à mudança do papel alocativo do Estado, especialmente no período após a Segunda Guerra Mundial. A partir daí, tem lugar o fortalecimento do chamado Estado de Bem-Estar Social (Welfare State), assentado na idéia de prestação de serviços por parte do Estado, de forma a compensar a desigualdade na distribuição do produto social. Neste período, a prosperidade esteve alicerçada no compromisso social para a ampliação dos direitos básicos da população. ${ }^{2}$

Nas décadas de 50 e 60, a idéia era a de que os Estados poderiam promover ajustes estruturais (EvANs, 1993:107). Entretanto, as mudanças demográficas, a crise fiscal, da sociedade do trabalho, as crises do padrão de acumulação e da organização da produção baseada no fordismo (com rompimento do círculo virtuoso entre redistribuição e acumulação) e ainda a agudização do conflito distributivo passam a compor o cenário. Com efeito, estes são alguns dos argumentos utilizados para explicar a crise do Welfare State no período seguinte (Melo e Costa, 1996: 155).

A partir dos anos 70 e 80, a tendência neoliberal passa a enfatizar a fragilidade da solução estatal para garantia do bem-estar social e da estabilidade econômica, preconizando a solução de mercado e fundamentando a idéia de Estado mínimo, com redução de sua estrutura administrativa (MELo e CosTA, 1996: 154). O cenário econômico engloba mudanças nos padrões de competição, em função da alteração do paradigma tecnológico, assim como a intensificação da globalização financeira. Aguça-se o movimento de esgotamento do padrão de acumulação fortalecido no pós-guerra.

O momento intelectual é o da discussão sobre a redefinição do papel do Estado. Os contextos social, político e econômico de crise do Estado apontam para reformas de fôlego, o que implica, sobremaneira, em alteração de estruturas organizacionais. 
Ademais, fortalece-se cada vez mais a idéia de que o modelo tradicional de gestão pública é ineficiente e que o modelo de gestão do setor privado é o ideal, favorecendo o surgimento de novas alternativas (ABRUCIO, 1997). O padrão burocrático de organização do Estado é colocado em xeque, com a emergência de um novo modelo, denominado pós-burocrático. ${ }^{3}$

Em síntese, os fatores elencados fragilizaram o Estado-Nação, agora com menos recursos e, relativamente, com menos poder.

\section{Visões da eficiência}

"Toda gestão econômica, dentro da economia de troca, é empreendida e levada a cabo pelos indivíduos economicamente ativos a fim de satisfazer interesses próprios, ideais ou materiais. Isso se aplica também, naturalmente, quando ela se orienta pelas ordens de associações econômicas ou reguladoras da economia (...) - é estranho que freqüentemente se desconheça esse fato” (WEBER, 1994:136).

Eficiência, no sentido econômico puro, pode ser definida com base nos estudos de Pareto sobre os mercados competitivos. A chamada "eficiência de Pareto" (ótimo de Pareto) é a situação em que, ao mesmo tempo, é impossível melhorar a situação de um indivíduo sem piorar a de outro, sendo três as condições para sua existência: eficiência nas trocas, na produção e na composição do produto. Esta última é sintetizada pela máxima de que a economia só deve produzir o que o consumidor quer comprar.

No contexto organizacional, agregam-se ao conceito de eficiência os de eficácia e efetividade, que, entretanto, nem sempre têm sido usados uniformemente. Há diversas concepções sobre tais termos, embora não discrepem excessivamente.

Junte-se a isto o fato de que, além das vertentes econômica e administrativa, a questão do desempenho organizacional, tem, também, uma vertente sociológica (SCHWARTZMAN, 1996). Assim, os sociólogos enxergam nos valores sociais a explicação da motivação pelo bom desempenho. ${ }^{4}$

Segundo os conceitos mais difundidos, eficiência está ligada ao melhor uso dos recursos da organização, de forma a obter seu produto ou serviço. Poderia ser sintetizada na relação entre o input real e o input padrão (o desejado pela organização), cujo resultado tenderia a zero.

Eficácia, por seu turno, refere-se à performance externa da organização, ao seu produto, ou seja, sua contribuição para o alcance dos objetivos organizacionais. Pode ser sintetizada na relação entre o output real e o output padrão, cujo resultado tenderia a infinito. 
Katz e Kahn (1987:169), por seu turno, consideram a eficiência como um dos componentes da eficácia. Entendem eficiência como a relação entre o produto (output de energia) e o custo (input de energia), referindo-se aos aspectos internos da organização. Eficácia é definida como a "maximização de rendimento para a organização, por meios técnicos e econômicos (eficiência) e por meios políticos" (KATZ e KAHN, 1987:183).

Cumpre destacar haver uma diferença importante entre eficiência operacional e eficiência adaptativa (ABRUCIO, 1997:21). Enquanto a primeira refere-se aos custos em sentido estrito, a segunda, por sua vez, incorpora o importante aspecto da flexibilidade. Neste sentido, é um conceito relacionado à dinâmica do mundo e das organizações, as quais, inseridas num contexto de mudanças, necessitam de significativa capacidade adaptativa.

Por seu turno, efetividade refere-se à relação, ao longo do tempo, entre os resultados alcançados e os objetivos pretendidos, sendo, muitas vezes, descrita como uma dimensão qualitativa do resultado (o valor social do produto). Sua mensuração, por ser essencialmente valorativa, é complexa.

Paulo Motta (s.d.) indica que há três dimensões básicas da efetividade. A primeira diz respeito à adequação, em que é verificado se os resultados apresentados correspondem às necessidades de que deram origem à ação; a segunda dimensão é a da eqüidade, que implica verificar se a ação implementada e os resultados obtidos permitiram uma distribuição mais justa dos recursos e dos benefícios; a terceira dimensão referese à propriedade política, ou seja, verificar se houve a satisfação das exigências e demandas da sociedade.

Por fim, um outro conceito importante e que, como veremos, será das peças principais em alguns modelos de gestão, é o de produtividade, o qual expressa a relação entre o produto de uma organização e os recursos utilizados para a sua obtenção. Reúne, pois, os conceitos de eficácia e eficiência, além dos de qualidade e tempestividade.

\section{Visões da burocracia}

“Como Keynes havia predito (...), a essência da burocracia moderna é que um sistema estável, equilibrado, produzindo lucros consistentes sem recorrer à expansão do capital, do pessoal ou da produção, está fadado a inspirar horror naqueles que o dirigem, e fadado a ser visto pela sociedade, mais genericamente, como uma operação 'morta'” (SENNETT, 1995: 400).

Segundo Girglioli (1995:124), o termo burocracia já surgiu com uma forte conotação negativa, numa reação à centralização administrativa e 
ao absolutismo, tendo sido empregado pela primeira vez por Gournay, economista fisiocrata, em meados do século XVIII. Designava o corpo de funcionários e empregados do Estado absolutista francês, sob a dependência do soberano e incumbido de funções especializadas.

O termo logo se difundiu, tendo sido, também, utilizado para atacar o formalismo e o espírito corporativo da administração pública, sobretudo na Alemanha (GIRGLIOLI, 1995:124).

Este elemento pejorativo acompanha o conceito de burocracia até os dias de hoje e, em que pese a enorme produção intelectual sobre o tema, não é rara a associação do termo a abundância de papéis, rigorosidade de normas, excesso de formalismo, etc. Não rara, também, a associação entre burocracia e ineficiência, como veremos a seguir.

Todavia, uma outra face do termo burocracia foi delineada no século XIX, a partir de estudos sobre o aparelho administrativo prussiano, organizado de forma hierárquica e monocrática, e que substituiu os antigos corpos administrativos colegiais. Esta face foi detalhada por Weber, cujos estudos serão apresentados mais adiante.

Para finalizar, não custa alinhar o que Warren Bennis (1967) chamou de ameaças à burocracia. São elas:

a) novos conceitos de poder, baseados na colaboração e não simplesmente na coerção e ameaças;

b) novos valores organizacionais baseados em concepções mais humanísticas, que podem substituir a impessoalidade;

c) mudanças ambientais rápidas e inesperadas;

d) crescimento (em tamanho e complexidade) das organizações;

e) complexidade da moderna tecnologia, que requer integração de atividades e pessoas, estas últimas com competências cada vez mais especializadas.

Considerando os cenários anteriormente esboçados, passemos à apresentação de diferentes formas de tratar a burocracia. Partiremos, em nosso estudo, da chamada tradição weberiana, passando pelas visões hegeliana e marxista, para alcançar, logo após, a corrente neoliberal. Estas não são as únicas formas de lidar com a questão, embora simplifiquem a abordagem do problema. A seguir, faremos algumas considerações sobre o insulamento burocrático e o paradigma agente-principal, relacionandoos, também, à questão da eficiência das burocracias.

\subsection{A tradição weberiana}

Max Weber tomou como objeto de estudo a burocracia, forma superior de organização social e de dominação (racional-legal), sendo, por muitos, considerado o principal porta-voz da idéia de a burocracia ser capaz de levar as organizações a atingirem maiores graus de eficiência 
(LANE: 1993:49). Tal associação, entretanto, não é enfática no sentido de estabelecer uma relação consolidada entre burocracia e eficiência. Frisemos, de antemão, que Weber trabalhou com a sociologia política e suas categorias e não com a teoria das organizações.

Entretanto, o tipo ideal weberiano (modelo analítico) reúne o que seria a modelagem de um sistema baseado em critérios de eficiência (considerando a estrutura formal da organização), dada por:

a) estrutura de autoridade impessoal;

b) hierarquia de cargos baseada em um sistema de carreiras altamente especificado;

c) cargos com claras esferas de competência e atribuições;

d) sistema de livre seleção para preenchimento dos cargos, baseado em regras específicas e contrato claro;

e) seleção com base em qualificação técnica (há nomeação e não eleição);

f) remuneração expressa em moeda e baseada em quantias fixas, graduada conforme o nível hierárquico e a responsabilidade do cargo;

g) o cargo como a única ocupação do burocrata;

h) promoção baseada em sistema de mérito;

i) separação entre os meios de administração e a propriedade privada do burocrata; e

j) sistemática e rigorosa disciplina e controle do cargo.

Todavia, essas características, na tradição weberiana, apenas tornam as burocracias capazes de alto grau de eficiência (LANE, 1993:49), cumprindo destacar, como demonstraremos mais adiante, que Weber parte de pressupostos diferentes dos da tradição neoliberal, vale dizer, enfatiza estruturas, regras, procedimentos, papéis, etc.

Weber foi pioneiro ao apontar o afastamento entre políticos e burocratas no Estado moderno (tipos ideais polares). Os políticos representavam inovação, ética de responsabilidade, etc; a burocracia, o "desencantamento do mundo" e a "rotinização do carisma" (Downs, 1967). Assim, as características típicas do líder político são opostas às do burocrata, que deve privilegiar seu dever de ofício. O político, por outro lado, deve demonstrar capacidade criativa e iniciativa política para o enfrentamento das questões. Nesta ordem de idéias, "os burocratas de Weber estavam envolvidos apenas na execução de suas atribuições e na contribuição ao cumprimento das metas do aparelho como um todo. O uso das prerrogativas oficiais para a maximização de interesses privados era, para Weber, uma característica de formas pré-burocráticas anteriores" (EvANs, 1993:115).

O trabalho basilar de Max Weber deu origem a toda uma tradição de pensar a burocracia, a qual foi fortemente marcante no período da chamada consolidação das bases do Estado keynesiano. A visão weberiana 
pura foi bastante criticada por várias escolas de pensamento em diversos campos de estudo, que procuraram demonstrar que a burocracia sofre uma série de disfunções. Exemplo clássico, no âmbito da Teoria das Organizações, é a crítica da Escola das Relações Humanas, que considera a estrutura informal primordial no alcance dos objetivos organizacionais. Assim, ao criticar o mecanismo básico do modelo weberiano, traz à tona a questão das relações, perspectiva tão cara, como mostraremos, aos defensores da autonomia inserida, ressaltando que os membros das organizações se influenciam reciprocamente, de forma a modificar os arranjos formais a que estão submetidos.

Ao analisar a burocracia em Weber, um ponto central levantado por Lane (1993) é o de que o pressuposto da impessoalidade mascara as reais motivações do burocrata. Neste sentido, argumenta que as burocracias não são impessoais, nelas existindo uma teia de relações humanas: "this [the transition from a personal relation to a impersonal one] may be a step towards more efficiency in an absolute sense. We have here a sort of fallacy: the fact that a bureaucrat is devoted do his/her office does not entail that the motivation problem is solved; it is still possible that the office holder is thus devoted because it maximizes his/her own personal utility or because he/she wishes the utility of the bureau. Both these objectives may not be conducive to efficiency" (LANE, 1993:50).

Duas outras críticas muito importantes (GIRGLIOLI, 1995:129) dizem respeito à concepção weberiana do tipo ideal e à análise microssocial das organizações. Em primeiro lugar, aponta-se que os elementos constitutivos do tipo ideal, por estarem colocados em diversos níveis de generalizações, não os tornariam adequados a uma análise das estruturas organizacionais. Nesta ordem de idéias, alguns elementos como, por exemplo, a especialização e o pagamento em dinheiro seriam próprios das administrações racionais (eficientes); outros, tais como a existência de staff administrativo e sistema hierárquico, caracterizariam a administração burocrática propriamente dita, categoria oposta à administração profissional. Os críticos apontam, ainda, que esta confusão entre burocracia e profissionalismo se estende ao conceito de autoridade, já que este se fundamenta na hierarquia (burocracia) e na competência (profissionalismo).

Em segundo lugar, as críticas assentam-se na afirmação de que o tipo ideal consiste em um esquema conceitual, que mistura a descrição das características que definem a burocracia a uma série de hipóteses, dentre elas, a de que a burocracia é capaz de maximizar a eficiência organizacional.

Acrescente-se à série infindável de críticas, principalmente no que diz respeito à questão da eficiência (GIRGLIOLI, 1995:129):

a) que a adesão dos funcionários às regras e normas burocráticas chega facilmente ao ritualismo e, conseqüentemente, à ineficiência; 
b) que a tomada de decisões que levem à eficiência fica prejudicada pela hierarquização, centralização e especialização, vez que estas tendem a distorcer informações;

c) que a capacidade de iniciativa dos subordinados fica seriamente limitada pela centralização e "determinação unilateral de conduta administrativa por parte dos superiores"; e

d) "que o modelo weberiano é muito mecanicista para ser eficiente em situações que exigem uma elevada capacidade de flexibilidade e de adaptação".

Todavia, cumpre ressaltar que a posição de Weber, baseada numa perspectiva histórica de descrição da realidade e de ênfase na estrutura formal, não se presta a definições sobre eficiência em sentido restrito. $\mathrm{O}$ tipo ideal é utilizado com propósitos comparativos e não é definidor ou determinante de uma condição de eficiência, acusação imposta a Weber. ${ }^{5}$ A questão é que a posição e os pressupostos de Weber tenderam a ser mal compreendidos por alguns de seus intérpretes, que insistem em considerar o tipo ideal além de suas limitações, impondo-o como solução para a organização da máquina burocrática estatal, independentemente das condições a que está submetida.

\subsection{A visão hegeliana}

$\mathrm{Na}$ perspectiva idealista de Hegel, a burocracia é componente de uma estrutura tripartite, juntamente com a sociedade civil e o Estado, servindo de elo entre os dois últimos. Como tal, teria por função básica a conciliação e a mediação entre o interesse geral personificado pelo Estado e os interesses particulares das corporações privadas, sendo desprovida de poder político (Tojal e CARvalho, 1997:53).

\subsection{A tradição marxista}

Marx descreveu a burocracia francesa da época de Luís Bonaparte como um "tremendo corpo de parasitas capaz de envolver com sua teia o corpo da sociedade" (apud Tojal e CARvalho, 1997:54).

As visões de Lenin e Trotsky não foram muito diferentes. Assim como Marx, não viam a burocracia como classe, sendo dependente de outras categorias da sociedade. Para Lenin, no socialismo, a extinção do Estado conduziria à extinção do aparelho burocrático, que entendia estar ligado à classe dominante. Trotsky considerava a burocracia como "uma formação eminentemente parasitária, que o povo poderia expulsar, no momento em que ela se revelasse ineficiente, como se expulsa um gerente incompetente" (Tojal e Carvalho, 1997:54). 
Vale, contudo, ressaltar que os teóricos do marxismo moderno reconhecem uma certa autonomia da burocracia, que pode agir em seu próprio interesse, contra alguns dos interesses da classe dominante.

\subsection{A visão neoliberal}

Perguntas como para que servem as burocracias ou se são elas eficientes foram priorizadas pelos neoliberais, que propõem um modelo de administração pública baseado na lógica de mercado, inspirada na filosofia liberal de Adam Smith.

Encontram abrigo nas construções teóricas da chamada Escola da Public Choice, cujos principais autores são Niskanen, Buchanan, Ostrom, Tullock e outros. Seu despontar ocorreu no início da década de 70, e o apogeu na década de 80, com o fracasso do mundo socialista e a crise do Welfare State. Os teóricos desta forte linha de pensamento partem do individualismo metodológico e discutem, com o instrumental econômico, as questões da burocracia pública. Utilizam, para tanto, conceitos como utilidade, eficiência econômica e maximização, analisando a relação que entendem simbiótica entre políticos e burocratas. ${ }^{6}$

O trabalho de Anthony Downs (1967) foi marcante na consolidação do tema na Escola da Public Choice, reforçando a tese de que os burocratas agem de forma racional, motivados, em especial, por seus próprios interesses (MoE, 1997:456). A categorização dos tipos comumente encontrados, quais sejam, zealots, advocates, climbers, conservatives e statesmen (Downs, 1967; MoE, 1997) é elucidativa, mostrando como a combinação desses tipos influi no ciclo de vida e no ciclo operativo das burocracias. $^{7}$

Para os neoliberais que rejeitam o modelo weberiano original, a burocracia pública tem uma imagem fundamentalmente negativa, baseada no fato de que:

a) negligencia o interesse público ao privilegiar os interesses particularistas de seus membros;

b) não promove o alcance de resultados socialmente relevantes, vez que a formulação e implementação de políticas públicas se dá de forma mais conveniente aos seus interesses e, por fim,

c) é perdulária com relação aos recursos públicos, à medida em que, no jogo político com o Legislativo, possui um raio de manobra que lhe permite cometer excessos. Assim, os burocratas seriam potencialmente rent seekers, procurando maximizar seus orçamentos. ${ }^{8}$

O neoliberalismo radicaliza a visão de que a burocracia é perniciosa, enfatizando que os burocratas procuram maximizar seus interesses e utilidades, como qualquer agente econômico. Essa visão da inexorabilidade da ineficiência burocrática acaba por entender que a burocracia opera 
sempre na produção de uma quantidade de serviços menor do que a esperada pelo Legislativo, não importando o sistema de incentivos a que está submetida.

A agência pública, que congrega os burocratas e oferta serviços públicos, seria maximizadora da relação entre os recursos de que dispõe e seus custos. Por constituírem uma elite especializada, os burocratas deteriam certa quantidade e qualidade de informação, que os colocaria em posição de vantagem em relação aos políticos. Esta assimetria de informação, dada pelos privilégios que possuem, propiciaria comportamentos oportunistas por parte dos burocratas e levaria a que a agência produzisse serviços numa quantidade inferior à esperada pelo Legislativo o que, pela racionalidade econômica, ocorreria no ponto em que os benefícios e os custos marginais se igualassem. Esta folga de recursos (slack) seria apropriada pelo burocrata.

\subsection{O insulamento burocrático}

Uma possibilidade de fuga da situação de ineficiência é a que se apresenta com o chamado insulamento burocrático, tentativa de isolar os laços que o aparelho burocrático mantém com o ambiente externo, de forma resistir às pressões clientelísticas e construir um "núcleo duro", capaz de garantir a governança. Na acepção de Ben Ross Schneider (1995:9), "a oportunidade dos servidores de seguir preferências e de formular políticas de forma independente".

Todavia, cumpre ressaltar que o afastamento excessivo pode conduzir ao tecnocratismo, apesar de fortes argumentos no sentido de ser o insulamento desejável para algumas carreiras, a fim de não serem capturadas por interesses privados; haver mecanismos institucionais para tanto, como, por exemplo, os concursos públicos; e ser, muitas vezes, concluído que o insulamento produz eficiência.

Por outro lado, os mecanismos de controle são fundamentais e reduzir a questão somente ao insulamento é uma parcialização perigosa. O que se deve buscar é um misto de colaboração e isolamento, evitando a ocorrência de extremos de permeabilidade e autonomia completas.

Na verdade, tanto Evans (1993) quanto Schneider (1995) relacionam a eficiência dos Estados a uma combinação entre isolamento e colaboração, a chamada autonomia inserida. Este conceito refere-se a elos estabelecidos com setores estratégicos, sendo extremamente diferente da autonomia completa, vale dizer, a situação em que as decisões são tomadas sem, nem mesmo, serem ouvidos os setores envolvidos. ${ }^{9}$

A autonomia inserida relaciona-se a "um conjunto concreto de laços sociais que amarra o Estado à sociedade e fornece canais institucionalizados para a contínua negociação e renegociação de metas e 
políticas" (EvAns, 1993:136). Nesta ordem de idéias, a eficiência estaria muito mais intimamente relacionada a uma burocracia inserida na sociedade, que combina a coerência interna à conexão externa (EvANs, 1993:150).

O insulamento burocrático não é a solução, assim como a autonomia inserida. ${ }^{10}$ Entretanto, parece salutar enxergar o insulamento como uma membrana semipermeável, capaz de atender aos requisitos do controle social e accountability. Deve-se estar atento para que o insulamento não conduza a patologias burocráticas irreversíveis. Há um limite tênue e o equilíbrio reside no fato de tratar-se de uma autonomia estrutural e não política. $\mathrm{O}$ insulamento aparece para evitar que a burocracia defenda interesses privados; entretanto, ela não pode ficar surda aos interesses coletivos. Neste sentido, importantíssimo é o papel desempenhado pela informação e pelos canais de comunicação entre o Estado e a sociedade.

Em perspectiva, há uma visão positiva dada por estudos menos radicais. A burocracia pode ser um instrumento de promoção do interesse público, desde que haja uma estrutura de incentivos adequada. Isto passa pela atitude do burocrata em relação à coisa pública, via um processo de internalização de normas culturais, atitudinais, etc. ${ }^{11}$

Peter Evans (1993) certamente conduz a uma leitura menos passional da tradição weberiana e leva a um posicionamento mais relativista acerca do sucesso ou insucesso de reformas administrativas baseadas nesse modelo de gestão pública. Ao tratar da questão da autonomia inserida, coloca as coisas no devido lugar: "a autonomia e a coerência corporativas, como o insulamento, certamente estão na tradição weberiana. A ênfase na ‘inserção' enquanto complemento necessário à autonomia não apenas contradiz a noção de que a insulação é a característica mais importante da capacidade, como também deriva de uma perspectiva weberiana (...) Admitir a importância da inserção coloca de pernas para o ar os argumentos em favor da insulação. As conexões com a sociedade civil se tornam parte da solução em vez de parte do problema" (Evans, 1993: 152-153).

\section{6. $O$ paradigma agente $x$ principal}

Um enfoque recente a respeito da burocracia enquadra-se no chamado neoinstitucionalismo, que "ao romper metodologicamente com pressupostos do comportamento maximizador e ao adotar o conceito de racionalidade constrangida (bounded rationality) (...) pode explorar o impacto da incerteza nas transações sociais" (Melo, 1996:70). Tais transações sociais envolvem o agente e o principal, quer sejam o Estado e os agentes econômicos privados, o Estado e os cidadãos ou ainda os burocratas (agentes do Estado) e os políticos (Melo, 1996:80). 
Behn (1995:318) destaca que os estudos sobre o relacionamento

entre os principais e seus agentes apontam para o deslocamento da preocupação com a motivação dos burocratas para a preocupação com o controle.

Com efeito, o paradigma agente $\mathrm{x}$ principal desloca a discussão da polarização Estado x mercado para o conjunto de incentivos com os quais os agentes se deparam. A relação agente-principal (governo-cidadãos) se dá por meio da regulação e os cidadãos podem controlar o governo via mecanismos de accountability, que significa fazer o governo responsável por suas ações. Assim, se o insulamento pode dar base a comportamentos oportunistas, o que os evita é o controle social, que faz com que se aja no sentido do principal.

\section{Diferentes modelos de gestão pública}

"The beginning of administrative wisdom is the awareness that there is no one optimum type of management system" (BURNS e STALKER, apud BEHN, 1995:322).

A partir das peculiaridades dos momentos históricos apresentados e das concepções acerca da burocracia pública e da eficiência, apresentamos diferentes formas de gestão pública, que se justificam pelo contexto histórico em que estão inseridas e pelo arranjo teórico que as suporta.

O modelo tradicional é o que mais se aproxima do tipo ideal weberiano. Organiza-se no sentido de imprimir à administração pública um caráter profissional e limitador ao clientelismo e ao patrimonialismo, possuindo como principais características:

a) centralização;

b) direção do topo para a base;

c) preenchimento dos cargos-chave por profissionais de carreira;

d) polarização políticos-burocratas;

e) pessoal contratado com base no mérito, etc. Este modelo orienta a construção de uma administração pública afastada da política e baseada no tipo ideal weberiano, características dos Estados desenvolvimentistas. ${ }^{12}$

A resposta neoliberal parte do pressuposto do Estado minimalista e submete a racionalidade burocrática à lógica de mercado, ficando a existência e a utilidade das organizações públicas determinadas pelas finalidades do mercado. As principais características do modelo liberal de gestão pública assentam-se em:

a) redução do tamanho do Estado, principalmente via privatização;

b) descentralização;

c) desregulamentação radical;

d) análise apurada de custo-benefício a orientar o processo decisório;

e) desestímulo à administração participativa; 
f) precariedade de relacionamento políticos-burocratas dada a assimetria de informações, etc.

As sugestões apresentadas por Niskanen para melhorar a eficiência das burocracias indicam reformas em suas estruturas, de modo a reduzir a assimetria de informação, que lhes confere vantagens. Prescreve um modelo que combina menos burocracia com mais operações baseadas em mecanismos de mercado, de modo a se obter maior eficiência. Como exemplo, temos o maior uso de empresas privadas para a provisão de bens públicos (LANE, 1993:62-63). Embora tais operações retirem das burocracias suas características weberianas, não há evidência empírica da validade de tal proposição. Ademais, "what matters beside efficiency is accountability and markets do not always perform better than bureaucracies in this respect" (LANE, 1993:63).

Por fim, não tardou a aparecer uma outra corrente, desta feita com uma visão gerencial. Em cena nos anos $80 \mathrm{e}$, como vimos, num "contexto de escassez de recursos, enfraquecimento do poder estatal e de avanço de uma ideologia privatizante" (ABRUCIO, 1997:13) baseia-se na introdução, na Administração Pública, de modelos empresariais, tendo como principais características:

a) orientação para clientes e resultados;

b) flexibilidade;

c) competitividade administrada;

d) descentralização;

e) Estado atuante, em contraposição à visão liberal;

f) orientação para critérios de eficiência via adoção de técnicas de administração de empresas (tecnologia gerencial);

g) estruturas horizontalizadas;

h) agências regulatórias independentes;

i) contrato de gestão, etc.

De certa maneira, esta nova forma de gestão surge como uma alternativa crítica ao modelo neoliberal, eis que, ao contrário deste, preconiza a existência de um Estado atuante, embora deva, também, estar orientado por critérios de eficiência empresarial (de mercado). Apresenta-se, outrossim, como uma alternativa crítica à forma tradicional de gestão pública. ${ }^{13}$

\section{Questões-chave em administração pública}

"Any field of science is defined by the big questions it asks" (BEHN, 1995:314).

Em que pese toda esta discussão sobre burocracia e eficiência, algumas questões fundamentais da administração pública permanecem e acompanham os estudiosos do tema, não importa o modelo de gestão 
pública em voga. Algumas delas tentam dar conta da eficiência; outras, no entanto, são mais gerais, embora tenham como norte a melhoria da prestação de serviços públicos.

Tais questões, quando relacionadas à administração pública, devem receber cuidados especiais, dadas as características peculiares da atividade pública, que está submetida a uma maior amplitude de escopo e impacto, devem ser sujeitas a accountability e, não esqueçamos, têm um caráter político (BENNIS, 1967).

Schwartzman (1996), por exemplo, resume as questões atinentes à reforma administrativa a duas perguntas: a) como garantir o bom desempenho das instituições? e b) como controlar as instituições de modo a que façam bom uso dos recursos públicos?

Ressalta que o bom desempenho não depende de controles restritos e centralizados, como é preconizado pelos tradicionalistas e, à primeira vista, parecem conduzir as perguntas acima explicitadas. O fato é que "a simples eliminação das restrições e controles burocráticos não é suficiente para garantir o bom desempenho e a correção no uso dos recursos públicos por parte das instituições governamentais" (SCHWARTZMAN, 1996:3).

Behn (1995) resume a três grandes questões o que os estudiosos da administração pública procuram responder em suas pesquisas: primeiro, como se desvencilhar do emaranhado de normas e procedimentos que impedem o alcance de resultados?; segundo, como motivar os funcionários para que ajam no sentido do alcance dos objetivos públicos?; e, por fim, como medir o desempenho das agências públicas e como melhorar os resultados atingidos?

Com efeito, isto é, como vimos, o que alguns dos modelos de gestão pública apresentados procuram atacar. Observe-se, por exemplo, que a questão da fuga de normas e procedimentos (perspectiva microorganizacional) aparece como uma reação à burocracia tradicional weberiana e que a questão da motivação aparece com muita força na Escola da Public Choice, sendo, no entanto, tratada na perspectiva econômica.

As três questões alinhadas por Robert Behn (1995) são interligadas. Assim, por exemplo, a questão da simplificação das normas está ligada à motivação, vale dizer, quando não se consegue motivar os indivíduos para que atinjam os resultados organizacionais, ou seja, quando não se consegue motivá-los para fazer a coisa certa, o resultado é tentar impedi-los de fazer a errada, o que se dá via proliferação de normas e procedimentos, a engessar a organização. ${ }^{14}$

Também George Frederickson (1971), no início dos anos 70, publicou instigante trabalho, sumarizando o movimento chamado New Public Administration e identificando questões-chave para a administração pública. Incorpora ao debate a questão da equiidade social no desempenho das organizações públicas, ressaltando a necessidade de 
existência de administradores pró-ativos, capazes de substituir os buro-

cratas "neutros". Acrescenta à clássica questão de como oferecer mais ou melhores serviços com os mesmos recursos disponíveis (eficiência) uma outra: a de se estes serviços aumentam a eqüidade social.

Para finalizar, cumpre frisar que estas grandes questões sempre existirão, podendo ser minimizadas em determinados momentos e maximizadas em outros. As soluções, no entanto, não são simples e cada uma pode ter múltiplas respostas, a depender do contexto em que são empregadas ou das características de seus implementadores (BEHN, 1995:322). Assim, encontrar uma solução para uma delas não exclui a existência de outras opções possíveis.

\section{Burocracia $x$ eficiência: um exemplo}

“(...) in recent years, economists have been particularly entrepreneurial — broadening the application of their favorite paradigms from the behavior of markets to the behavior of organizations” (BEHN, 1995:318).

Pela sua importância, escolhemos o caso britânico para ilustrar uma resposta ao esgotamento do modelo burocrático-weberiano e à eterna luta burocracia x eficiência, denominada gerencialismo ${ }^{15}$ e que, segundo Abrucio (1997:8), insere-se num contexto mais amplo, relacionado à centralidade do tema "reforma administrativa".

Com a vitória do Partido Conservador em 1979, a Grã-Bretanha experimentou um redirecionamento da concepção de Estado até então vigente e a introdução de novos mecanismos de gestão pública. Nesta perspectiva, foi concebido um modelo baseado na busca da eficiência, cujos principais objetivos se assentavam no corte de gastos, sobretudo os relativos a pessoal.

A experiência inglesa, ao abrir os caminhos para a discussão sobre as mudanças nas formas de gestão pública e ao introduzir o gerencialismo (o padrão gerencial de administração pública) na agenda de reformas, foi elemento basilar em reformas administrativas realizadas em diversos países, os quais, a partir de suas peculiaridades locais, têm utilizado alguns dos pressupostos gerencialistas para modificar suas estruturas administrativas.

Este modelo privilegia o desempenho organizacional, os resultados e o "gerenciamento" dos recursos (humanos, materiais, financeiros e informacionais), palavras-chave para o estudo da eficiência, em detrimento da "administração de atividades, normas, procedimentos, etc (Pollitt, 1993:49). ${ }^{16}$ 
É bem verdade que a implantação do chamado modelo gerencial passou por diversas etapas na Grã-Bretanha, indo desde o chamado gerencialismo puro até o Public Service Orientation (PSO), passando pelo consumerism. A cada etapa, aspectos positivos foram incorporados, conformando o chamado Managerialism ou Public Management.

O gerencialismo puro, pelas suas características (principalmente no que diz respeito à relação burocracia-eficiência), é o que mais se aproxima da forma liberal de gestão pública. Por outro lado, as fases posteriores do consumerism e $P S O$ melhor se enquadram no chamado empreendedorismo.

Na concepção inicial, o gerencialismo viria a substituir o modelo weberiano tradicional, tornando o aparato estatal mais flexível e adaptável às mudanças sociais, econômicas, políticas, culturais e intelectuais que se apresentavam. Era um modelo desestatizante. O caminho seria a introdução da lógica da eficiência e produtividade, característica do setor privado, de forma contentar os contribuintes (taxpayers), cujos votos sinalizaram a disposição para a mudança.

No caso do gerencialismo puro, isto foi levado muito a sério e a vertente economicista, com uma visão de eficiência fortemente ligada ao corte de gastos (lógica econômica estrita), ganha muito espaço. Neste sentido, sintomática foi a entrega do comando da reforma administrativa a um bem-sucedido administrador privado, capaz de trazer ao setor público a experiência da gestão privada no trato das questões de eficiência, criando um novo padrão organizacional de modernização.

O fato que gostaríamos de destacar, entretanto, é que a utilização de mecanismos de mercado como tecnologia administrativa para reformas não deve ser visto como que livre de uma forte influência ideológica (FLYNN \& STREHL, 1996:4). No caso inglês, o pressuposto era o de que o modelo burocrático tradicional não mais respondia às necessidades colocadas e que, somente por meio de estratégias utilizadas com sucesso pela iniciativa privada, poderia o setor público atender às demandas dos contribuintes.

Utilizando a tese machadiana das idéias grávidas ${ }^{17}$, poderíamos supor que a idéia de reforma do Estado, naquele momento histórico, trazia em si a idéia de eficiência, eis que, na crença de que o setor público, da forma como estava estruturado, não poderia mais atender aos imperativos que se apresentavam, as soluções baseadas nas práticas privadas, apareciam como salvadoras.

Ao enfatizar a "opção preferencial pela eficiência", o gerencialismo puro deixou claro que o seu "inimigo" era a velha engrenagem da burocracia tradicional, que, embora enferrujada, ainda era dominante no setor público inglês. 
Propunha, desta forma:

a) a definição das responsabilidades de cada um dos atores inseridos nas agências governamentais;

b) a definição dos objetivos organizacionais; e

c) a incorporação da "consciência dos custos", ou seja, estímulo a que os funcionários públicos conhecessem o custo de suas ações (Abrucio, 1997).

Os principais instrumentos utilizados para o alcance dos objetivos, tendo como pano de fundo a estratégia da eficiência, foram:

a) avaliação de desempenho;

b) introdução de técnicas de controle orçamentário;

c) descentralização administrativa;

d) delegação de autoridade aos funcionários (empowerment); e

e) administração por objetivos (ABRUCIO, 1997).

Os êxitos do gerencialismo puro, intimamente relacionados à estratégia de eficiência em sentido estrito, localizaram-se no corte de gastos com pessoal, via redução do número de funcionários tanto do Poder Central quanto das empresas estatais (empresas nacionalizadas e empresas públicas, como resultado das privatizações), assim como no incremento verificado na chamada "consciência de custos" da burocracia britânica. ${ }^{18}$

Todavia, o gerencialismo puro também enfrentou críticas importantes, fundadas, principalmente, na rígida estratégia de busca de eficiência (a mesma que incrementou a "consciência de custos"). Assim, este modelo fracassou de alguma maneira, o que determinou sua imediata revisão e evolução. O que se discutirá adiante é a intensidade com que tal estratégia foi implantada, o que, muitas vezes, mascarou os ganhos obtidos com sua utilização.

Um ponto interessante diz respeito ao que se poderia chamar “engessamento pela eficiência". Tal situação extrema seria alcançada quando, ao enfatizar ilimitadamente a dita estratégia, o gerencialismo puro caísse na "armadilha da eficiência". Assim, critérios rígidos de definição, implementação e avaliação da eficiência impediriam o afloramento dos meios naturais para seu alcance, quais sejam, a flexibilidade e a capacidade inovativa.

Nesta ordem de idéias, considerar a eficiência apenas sob o aspecto dos custos não necessariamente é o melhor critério. A lógica econômica a todo custo pode ser incompatível com a lógica gerencial.

Ademais, a ênfase na eficiência econômica obscureceu um aspecto importante que é o da efetividade, pois, em se tratando de serviços públicos, de que vale ser eficiente quando não se é efetivo? Não sendo um conceito econômico, como é a eficiência no sentido do puro gerencialismo, o conceito 
de efetividade incorpora o aspecto político da prestação dos serviços. Alie-se a isto o fato de que, aos conceitos de valor social e qualidade da prestação, acoplam-se perfeitamente os de eqüidade e justiça, os quais também não são quantificáveis e, muito menos, avaliáveis via instrumental oferecido pelo modelo gerencial puro.

Outro aspecto que merece ser destacado nesta análise da estratégia de eficiência do gerencialismo em seus primórdios diz respeito ao fato de apregoar ser a administração gerencial uma técnica neutra e pura. Decorre daí a separação entre política e administração, que não é teórica nem empiricamente sustentável. Ademais, criou incentivos para que as técnicas gerenciais aplicáveis ao setor privado fossem, sem maiores considerações, transplantadas para o setor público.

Isto provocou sérios conflitos, tanto na defesa da consistência interna do modelo, quanto no âmbito das organizações em que foi aplicado. A base está em duas ordens de argumentos. Em primeiro lugar, por ser a lógica do setor público diferente da do setor privado (a esfera privada possui objetivos e motivações peculiares, claramente diferentes da lógica pública). Em segundo lugar, tratar o modelo gerencial como uma técnica neutra, capaz de modificar a cultura e o funcionamento da administração pública, poderia conduzir à dedução lógica de que o gerencialismo puro, sob este aspecto, não passaria da tradição weberiana com outro nome (lembremos que a neutralidade era uma das peças principais da tradição burocrática, que o gerencialismo puro procurava combater).

Assim procedendo, o modelo gerencial puro se fragilizou, vez que ficou cego às diferenças profundas existentes entre a administração privada e a pública, onde reina uma intrincada teia de relações com a esfera política. ${ }^{19}$

Para finalizar, a principal crítica oferecida à estratégia da eficiência do puro gerencialismo inglês, e a mais brilhante em nosso entendimento, é a que o relaciona ao taylorismo, movimento por uma administração científica, capitaneado por F. Taylor no início deste século. Responsável pelo delineamento de uma corrente importante da teoria das organizações, denominada administrativista, o taylorismo preocupava-se com a prática administrativa, focalizando a gestão.

Christopher Pollitt (1993), ao analisar o modelo gerencial, classificou-o como "neotaylorista", por identificar, na proposta da busca incessante da produtividade e eficiência, nos instrumentos privados utilizados para tanto e na ênfase excessiva em uma cientificidade (entendida como neutra e separada da política), a mesma lógica que moveu os estudos e proposições de Taylor.

Os implementadores do modelo partiram do pressuposto conhecido de que um sistema considerado eficiente seria aquele que produzisse 
maiores quantidades de bens a partir de uma redução dos custos de produção. Acreditavam, assim como os tayloristas puros, na existência de one best way, alcançável por meio da racionalidade instrumental. Havia, ademais, o pressuposto econômico de que os agentes são racionais e maximizadores de recursos, preferências, utilidades, etc. Usaram, então, o conhecimento sobre a administração científica aplicada à produção industrial para definir a concepção de uma administração pública eficiente.

Entretanto, o conceito de produto na indústria não pode ser transplantado assim tão facilmente para a administração pública. É claro. São diferentes. Na esfera industrial, a etapa de produção de bens é claramente separada da etapa de distribuição e consumo dos mesmos. Na esfera pública, ao contrário, muitos serviços são produzidos, distribuídos e consumidos durante o mesmo processo e, muitas vezes, os destinatários destes serviços participam da produção (BARZELAY, 1992).

Há, ainda, algumas outras implicações importantes nesta designação de "neotaylorismo". Vejamos. Uma das principais características do taylorismo é a chamada alienação do trabalhador, dada pela separação entre trabalho manual e intelectual (realizado, respectivamente, pelos blue e white collars). Do mesmo modo, no gerencialismo, há o abismo entre formulação e implementação (tendo por pano de fundo a separação entre política e administração). ${ }^{20}$

Ademais, o único incentivo que se entende no taylorismo é o salarial, não incorporando outros aspectos motivacionais importantes. Isto redundou, por exemplo, no caso do gerencialismo puro, na falta de um projeto que envolvesse o alto escalão na estratégia de reforma, o que provocou alto grau de incerteza.

É possível observar, todavia, que alguns dos aspectos frágeis do gerencialismo puro, que elencamos neste espaço, foram revistos nas fases subseqüentes do modelo gerencial inglês. A segunda fase do modelo, chamada consumerism (New Public Management), deu-se no sentido da qualidade e da flexibilidade, que haviam sido negligenciadas pelo gerencialismo puro.

Em que pese a importante mudança de objetivos, verificada quando se compara o consumerism com o modelo gerencial puro, a principal inovação ocorreu no sentido da redefinição do público-alvo, que passa do contribuinte para o cliente/consumidor. A focalização no consumidor e a introdução da abordagem qualitativa na gestão pública foi, sem dúvida, um passo importante no sentido da recuperação do conceito de público, o que, entretanto, só será melhor trabalhado na terceira fase do modelo gerencial inglês, denominada Public Service Orientation (PSO).

$\mathrm{O}$ aumento do poder do consumidor dar-se-ia, por exemplo, via o incremento da descentralização administrativa (esta foi uma idéia trazida do gerencialismo puro), sob o argumento de que, ao levar a execução do 
serviço público para mais perto do consumidor, este teria melhores condições de fiscalização da prestação. Conseqüentemente, haveria uma melhora significativa da qualidade dos serviços públicos.

Associada à descentralização, a competição entre as agências públicas era entendida como capaz de levar a um maior poder do consumidor, visto que evitaria a situação de monopólio, danosa à prestação de serviços públicos de qualidade.

Existe, todavia, um problema conceitual no consumerism, que é justamente o que origina seu nome. $O$ conceito de consumidor não responde satisfatoriamente a algumas questões colocadas.

Antes de alinhar os principais problemas verificados com relação a este conceito, cumpre reforçar a idéia de que, ao utilizar técnicas do setor privado, o gerencialismo trouxe, em seu bojo, o conceito mais importante das estruturas de mercado: competição. Isto gerou algumas disfunções no modelo, comprometendo, por exemplo, a realização da eqüidade, essencial em se tratando da esfera pública.

Primeiramente, salta aos olhos a dedução de que o consumidor de serviços públicos é diferente do consumidor de serviços privados, vez que, como já destacamos, a esfera pública é diferente da esfera privada. A racionalidade econômica não deve comandar o relacionamento entre o prestador e o usuário de serviços públicos. Ademais, valores importantes como justiça, eqüidade e interesse público tornam o domínio público diferente do privado.

Ora, também os serviços públicos são intrínsecos e naturalmente desiguais. $\mathrm{O}$ sistema de competição entre serviços pode criar uma distribuição injusta de recursos, em que os melhores avaliados pelo "consumidor" receberiam mais recursos, enquanto os piores, menos. Esta lógica de soma zero conduz as organizações com pior desempenho a um movimento descendente e as com melhor desempenho a um movimento ascendente em importância e destinação dos recursos, aumentando a disparidade entre elas. Tal situação acarretaria prejuízos para os usuários dos serviços públicos e para a sociedade como um todo.

O fato de os consumidores poderem ser organizar também impõe uma lógica perversa. Neste modelo de incentivo à competição, a desigualdade a que são submetidos pode piorar sua posição social, vez que, normalmente, os mais organizados vencem a competição. O interesse público pode estar comprometido, dado que, ao se organizarem, os consumidores exercerão maior pressão sobre os burocratas, os quais, vislumbrando a avaliação a que serão submetidos, render-se-ão ao grupo, de modo a satisfazer-lhes as reivindicações (para, em última análise, preservarem suas próprias posições).

Neste sentido, o papel coordenador do Estado é fundamental, não tendo sido, entretanto, enfatizado neste modelo. O consumerism não se 
desvencilhou da lógica de mercado e assumiu a lógica pública. A lógica econômica da eficiência continua prioritária. Ao vencedor, tudo.

Ademais, quem é o consumidor na teoria econômica? Tal conceito traz em si uma característica de exclusão. No mercado, por óbvio, é consumidor aquele que é capaz de consumir bens e serviços. Entretanto, é indispensável ressaltar que só é capaz de consumir bens e serviços quem é detentor de recursos financeiros para tanto. O consumidor, por definição, é aquele capaz de escolhas racionais, maximizando utilidades. O pressuposto da competição é a garantia de alternativas exeqüíveis à disposição dos consumidores, de forma que possam escolher as que mais lhes agradem em termos de qualidade, comodidade, etc.

A mesma lógica aplicada aos serviços públicos pode conduzir ao seguinte raciocínio: é consumidor de serviços públicos aquele que possui características especiais que o tornam diferente dos demais atores sociais. No caso, aquele com capacidade de competir em condições mais favoráveis, ou aquele que esteja sob a jurisdição de uma agência pública que, por seu desempenho anterior, tenha recebido recursos suficientes para continuar operando. Ocorre que, em se tratando de serviços públicos, nem sempre há possibilidade de escolha universal.

Desta forma, alguns podem se tornar "mais consumidores do que outros" ou "clientes preferenciais do serviço público" (ABRUCIO, 1997:28). No limite, podem se tornar "mais cidadãos do que outros", se utilizarmos o conceito de cidadão em substituição ao de consumidor, como propõem alguns autores. ${ }^{21}$

Toda esta confusão de conceitos pode ser decorrente do desconhecimento (ou descaso) sobre o conceito de público na administração pública. Esse é um terreno bastante movediço e este não é o espaço mais adequado para discuti-lo. Entretanto, a ressalva é importante, pois, a depender do arcabouço teórico e ideológico a sustentar as reformas administrativas, diferentes conceitos de público serão apresentados, podendo ser consumidor, grupo de interesse, cidadão, etc. Desta forma, é perfeitamente compreensível (embora discutível) a utilização do conceito de consumidor pelo New Public Management, dada a lógica de mercado que o informa.

Utilizar o conceito de consumidor, já vimos, traz em si uma concepção de indivíduo movido por uma racionalidade econômica. Assim, o único motivo para uma ação coletiva seria a promoção de interesses pessoais e, neste sentido, o único propósito das agências públicas seria o de satisfazer os requisitos destes consumidores individuais. $\mathrm{O}$ pressuposto a informar tal dedução é o de que os consumidores têm habilidades equivalentes para expressar seus desejos e ainda que tais desejos são relativamente estáveis no tempo. 
Tal raciocínio conduz à conclusão de que a accountability é garantida, primariamente, pela ação do mercado, vale dizer, a "mão invisível", as forças da competição, conduziriam as organizações públicas à produção de resultados de qualidade.

É interessante notar que a ênfase na eficiência, na competição e na soberania do consumidor pode conduzir a uma lógica às avessas, que retira o Estado dos locais mais necessitados, onde poderia exercer, em plenitude, seu papel. Excluir pessoas pelo critério da competitividade não representa a melhor saída em direção ao alcance do interesse público.

As críticas ao consumerism motivaram a concepção da Public Service Orientation, baseada na defesa da descentralização por suas virtudes políticas e na idéia de reconstrução da esfera pública. ${ }^{22}$ Cumpre, entretanto, destacar que a idéia de eficiência já não é mais tão radical nesta fase do modelo inglês, embora continue sendo central, assim como a ênfase na visão gerencial. ${ }^{23}$

Para a fuga da armadilha do conceito de consumidor, a PSO trabalha com o conceito de cidadão, vez que cidadania implica não só liberdade de escolha de serviços públicos (como é o caso do conceito de consumidor), como também exercício de direitos e deveres, relacionando-se ao conceito de accountability (ABRUCIO, 1997:27).

Flynn e Strehl (1996:17) citam o exemplo da França, que utiliza o conceito de cidadão-usuário (citizen-user). A combinação reflete a face consumidor e a face cidadão do usuário dos serviços públicos. Assim, ao mesmo tempo em que privilegia o direito de ter preferências e de agir conforme a utilidade delas decorrentes (no sentido econômico, procurando atingir curvas de indiferença mais altas), privilegia, também, os direitos do cidadão, definidos como a capacidade de influenciar as ações governamentais (cidadão entendido, no mais das vezes, como eleitor). Todavia, outro problema se coloca: quem é cidadão?

\section{Considerações finais}

Há diferentes formas de enfrentar a questão do relacionamento entre burocracia e eficiência e muitas delas têm sido usadas. O que se há de reter, neste trabalho, é a identificação das idéias que estão por trás de cada proposição de reforma, vale dizer, quais são as bases teóricas sobre as quais se assentam. Assim, temos um largo espectro de proposições que vão desde um repensar pouco profundo das chamadas bases tradicionais até uma reflexão mais acurada e a incorporação de idéias e conceitos de outros campos de estudo, criando uma nova forma de lidar com as questões-chave em administração pública. 
O fato é que, sobretudo quando se trata de sociedades complexas, as reformas não podem ser vistas sob um ângulo totalizante. Estratégias de gestão, per si, não são neutras, envolvendo valores, preferências, opções, etc. Por outro lado, reformas administrativas também não são neutras, abrangendo diversos atores, que também têm valores, experiências, interesses, etc. ${ }^{24}$ Destarte, não há neutralidade no comportamento dos atores e, muito menos, no momento da escolha dos instrumentos de gestão.

Devemos reconhecer que a eficiência do setor público e a capacidade do Estado de formular e implementar políticas públicas dependem de sua estrutura administrativa e da estrutura social na qual está inserida. Com o Estado keynesiano, o setor público moderno se formou. Entretanto, como vimos, as recentes reformas administrativas apontam para um movimento de "desconstrução" deste Estado. Chegamos a uma situação que configura o paradoxo do neoliberalismo, qual seja: para reduzir o tamanho do Estado (para ter o Estado mínimo) é preciso ter uma Estado forte.

A contemporânea teoria das organizações tem colocado em xeque a capacidade da teoria weberiana de produzir eficiência. Todavia, Evans (1993:150) apresenta a situação das organizações patrimoniais se disfarçarem em burocracias weberianas, confirmando sua tese de que a burocracia está em escassez de oferta. Para ele, "o nítido contraste entre o caráter pré-burocrático, patrimonialista do Estado predatório e o caráter mais estreitamente weberiano dos Estados desenvolvimentistas deveria provocar dúvidas naqueles que atribuem a ineficácia dos Estados do Terceiro Mundo à sua natureza burocrática. A falta de burocracia pode estar mais próxima do diagnóstico correto" (Evans, 1993:135). Por sua vez, Terry Moe (1997) enfatiza que a burocracia, por si mesma, tem merecido menos atenção do que deveria. ${ }^{25}$

A questão da eficiência pura deve ser revisitada. A esfera pública deve estar apta a promover o equilíbrio entre os interesses que informam a vida e a organização dos diversos grupos sociais, que, embora possuam diferentes níveis de recursos e motivações, devem ser atendidos equitativamente. ${ }^{26}$

Weber indicou ser objetivo da burocracia alcançar os fins do Estado, ou seja, a efetividade. É claro que atingir os fins esperados a qualquer preço levará, fatalmente, à ineficiência. Contudo, privilegiar o "preço" em detrimento dos fins esperados, certamente, também conduzirá à ineficiência. 
1 Trabalho final do Curso de Formação para a Carreira de Especialista em Políticas Públicas e Gestão Governamental, realizado na Escola Nacional de Administração Pública (ENAP), em Brasília, no período de março a agosto de 1997. Versão simplificada deste trabalho recebeu Menção Honrosa no $4^{\circ}$ Concurso de Casos e Textos promovido pela FESP/RJ. A autora agradece aos professores Marcus André Campello de Mello e Fernando Luiz Abrucio pelas sugestões oferecidas.

2 Este cenário do pós-guerra foi propiciador de um ambiente intelectual "dominado pelos economistas que não têm a liberdade individual como principal valor para a constituição da sociedade, aqueles que não atribuem ao mercado um valor positivo e que acreditam na superioridade do controle de uma instância reguladora sobre as liberdades individuais" (TONETO Jr., 1996:131). Isto irá influenciar fortemente, como veremos, o trabalho de James Buchanan e dos demais teóricos da Public Choice. No Brasil, especificamente, é um período de marcada hipertrofia do Poder Executivo, em que a constituição de uma burocracia forte, capaz de suportar um Estado altamente intervencionista, quer no campo econômico, quer no social, o elemento basilar.

3 "Contribuía ainda mais para piorar a imagem da burocracia o fato de ela ser classificada, à época, muito mais como um grupo de interesse do que como um corpo técnico neutro a serviço do cidadão" (ABRUCIO, 1997:12-13).

4 Tal preocupação seria, por exemplo, na justificativa weberiana, fruto da ética protestante de busca da realização terrena, com vistas ao alcance da salvação divina.

5 "Neste sentido (...) a tão citada afirmação weberiana, segundo a qual a administração burocrática é coeteris paribus, tecnicamente superior às demais, vale somente na medida em que a burocracia é comparada com os típicos aparelhos do domínio tradicional e carismático" (GirgLioli, 1995:56).

6 A Public Choice "é uma extensão da teoria econômica tradicional à análise do processo político" (TONETO JR., 1996: 130-131).

7 Vale, também, apresentar parte da tipologia de Alvin Gouldner (KASZNAR, 1996:13-4), que distinguiu dois tipos de profissionais, que chamou locais e cosmopolitas. Os primeiros são os que associam sua identidade pessoal e derivam seu senso de poder a fatores endógenos à organização. Podem ser divididos em quatro subtipos: locais dedicados, verdadeiros burocratas, membros da guarda e amigos. Por sua vez, os cosmopolitas preocupam-se com fatores externos à organização, sendo considerados mais profissionais. Acrescenta que a combinação entre locais (burocratas) e cosmopolitas (profissionais) pode levar a oportunidades de inovações organizacionais bem-sucedidas.

8 De fato, o desperdício não significa que o burocrata se aproprie dos recursos colocados à sua disposição (no sentido de embolsá-los), mas a apropriação acaba ocorrendo quando, por exemplo, adquire bens de que não necessita (adquire, por exemplo, símbolos de poder), o que contribui para reforçar sua posição na esfera executiva. Acrescente-se que, na verdade, há, também, uma racionalidade dos políticos, orientada pela busca de votos com vistas à reeleição (seriam, também rent seekers, já que procuram maximizar sua posição eleitoral. Neste sentido, poderiam ser chamados vote seekers).

9 Os burocratas considerar-se-iam oniscientes.

10 “ (...) é a combinação de inserção e autonomia que funciona e não cada uma por si mesma” (Evans, 1993:153). 
11 Segundo Schneider (1995), é a postura individual do burocrata que pode fazer com que sua relação com o setor privado não seja predatória. Todavia, tal postura será adotada não por uma questão moral, de ethos, mas porque entenderá que pode ganhar com isto. A diferença residiria na definição das regras do jogo, que, sendo claras, podem incentivar os burocratas a segui-las.

12 Todavia, o caso brasileiro, por exemplo, teve a construção da coerência corporativa weberiana impedida pela existência de fortes características clientelistas e patrimonialistas, com uma parcialização da autonomia inserida, restrita a "bolsões de eficiência" (Evans, 1993: 145).

13 “Ora, se a proposta de um Estado mínimo não é realista, e se o fator básico subjacente à crise ou à desaceleração econômica e ao aumento dos níveis de desemprego é a crise do Estado, a conclusão só pode ser uma: o caminho para resolver a crise não é provocar o definhamento do Estado, enfraquecê-lo ainda mais do que já está enfraquecido, mas reconstruí-lo, reformá-lo” (Bresser Pereira, 1996:5). E ainda: “(...) a administração pública gerencial (...) parte do pressuposto de que já chegamos em um nível cultural e político em que o patrimonialismo está condenado, que o burocratismo está condenado, e que é possível desenvolver estratégias administrativas baseada[s] na ampla delegação de autoridade e na cobrança a posteriori de resultados" (BRESSER Pereira, 1997:7).

14 “(...) effective measurement of the consequence of a public agency's efforts can motivate the people working in that agency to do a better job and can, at the same time, provide the evidence necessary to build trust in the agency and thus break the micromanagement cycle" (BEHN, 1995:321).

15 Poderíamos, também, utilizar o exemplo dos Estados Unidos que, a despeito de terem experimentado um padrão mais residual de Welfare State, também preconizaram reformas de cunho liberal, de orientação gerencial e ainda mais descentralizadoras do que a inglesa. O caso brasileiro não é, aqui, utilizado por estar em implantação, dependendo de reforma constitucional para sua completa viabilização. Aliás, passada a posição inicial em direção ao gerencialismo puro, já é admitida, nos textos mais recentes, a necessidade de algum núcleo burocrático tradicional. O gerencialismo tinha uma visão de que para se chegar à eficiência era necessário sair da burocracia. Todavia, no caso brasileiro, em particular, a proposta de administração do núcleo estratégico do Estado é parte burocrática e parte gerencial (BRESSER PEREIRA, 1997: 22).

16 As teorias da administração pública indicam diversos estudos sobre o tema e demonstram que alguns dos pressupostos do gerencialismo não são tão novos como se supõe. Veja-se, por exemplo, os estudos de Burns \& Stalker, na década de 60, que identificaram duas formas diferentes de organizações: as mecanicistas, em que as tarefas são estritamente definidas e as normas e procedimentos que são claros e seguidos à risca, com pouca margem de flexibilidade; e, por contraste, as orgânicas, caracterizadas pela redefinição contínua das tarefas, utilizando canais de comunicação que são muito mais horizontais do que estritamente vinculados à verticalidade hierárquica (BEHN, 1995:318). O trabalho de Warren Bennis (1967) também merece ser destacado, pois, já na década de 60, considerava a necessidade de flexibilização das organizações.

17 “(...) as idéias dividem-se em três classes, umas votadas à perpétua virgindade, outras destinadas à procriação, e outras que nascem já de barriga. Esta divisão explica toda a civilização humana. Para onde quer que lancemos o olhar, qualquer que seja a raça, $o$ meio e o tempo, acharemos a genealogia distinta destas três classes de idéias, isto desde o princípio do mundo até a hora em que a folha sair do prelo. Assim, a idéia de Eva, quando resolveu desobedecer ao Senhor, vinha já grávida da idéia de Caim. Ao contrário, a minha idéia de possuir duzentos contos morre com o véu de donzela, a menos que algum leitor opulento a queira fecundar" (MACHADO DE Assis, 1996:62). 
18 Entretanto, uma análise mais cuidadosa da evolução do quadro de pessoal britânico mostrará que, na verdade, o tão propalado sucesso no corte de pessoal não foi pleno (ABrucio, 1997). Na área social, houve um aumento do número de funcionários, enquanto o corte de pessoal no poder local, a ponta da linha, onde efetivamente os serviços são prestados, foi bastante pequeno. Os principais cortes localizaram-se no chamado Civil Service (excluído o National Health Service).

19 O sucesso das reformas administrativas sempre dependeu do apoio político, vide, por exemplo, o fracasso da reforma administrativa implementada pelo presidente Reagan nos Estados Unidos, decorrente do fato de ter negligenciado a politização da administração (ABRUCIO, 1997). Neste ponto, cumpre ressaltar que, se o modelo inglês foi bemsucedido, isto se deu por força da política. Paradoxalmente, o gerencialismo puro subestimava este aspecto político.

20 Nas fábricas organizadas sob a ótica taylorista, a produção era controlada por um forte sistema hierárquico (cadeia de comando) e havia uma separação nítida entre o "saber" e o "fazer". Os "tempos e movimentos" e a neutralidade científica garantiriam a eficiência.

21 Também na fase do consumerism chegou a ser proposto, por alguns autores, a substituição do termo consumidor pelo termo cidadão, discutindo-se o conceito de accountability. Entretanto, esta pressupõe uma participação ativa em todas as fases da provisão do serviço e não só na de controle, como foi a solução encontrada pelo consumerism. Cabe, ainda, ressaltar que, do mesmo modo em que no modelo tradicional, houve um distanciamento do Estado da sociedade, já que os pressupostos do consumerism criaram uma atitude passiva em relação aos mecanismos de accountability, havendo pouca possibilidade de participação ativa do usuário.

22 “(...) vista como local de aprendizagem social. Isto é, a esfera pública não é só o locus por excelência da participação dos cidadãos, mas sobretudo onde os cidadãos aprendem com o debate público" (ABrucio, 1997: 30).

23 "O Public Service Orientation (PSO), embora retome temas pouco discutidos ao longo da década de 80, não propõe a volta de um modelo pré-gerencial, burocrático weberiano. (...) procura encontrar novos caminhos abertos pela discussão gerencial, explorando suas potencialidades e preenchendo boa parte de suas lacunas" (ABRUCIO, 1997:29).

24 Na maioria das vezes, implicam embate entre os atores.

25 "too often, bureaucratic theories are really not pursued for what they can tell us about bureaucracy, but rather for what they can tell us about how much power Congress and other authorities have and what mechanisms they employ to get their way" (MoE, 1997:480).

26 "[efficiency and cost-consciousness] (...) will always be important, but they only take on their full meaning within a context in which the broader purposes of a public service are discussed and defined, and a concern with effectiveness assumes greater salience. (...) it is possible to run a concentration camp economically and efficiently but that does not make it a desirable public service" (PoLLitT, 1993:192). 


\section{Referências bibliográficas}

Abrucio, Fernando Luiz. O impacto do modelo gerencial na Administração Pública: um breve estudo sobre a experiência internacional recente. Cadernos ENAP. Brasília, ENAP, número 10, 1997.

BARZELAY, Michael. Breaking through bureaucracy: a new vision of managing in government. California, University of California, 1992, cap. 8.

BeHn, Robert D. The big questions of public management. Public Administration Review. Washington, DC, American Society of Public Administration, 55(4):313-324, jul./ aug. 1995.

Bennis, Warren. Organizations of the future. In: Shafritz, Jay M. \& Hyde, Albert (ed.). Classics of Public Administration. 3 ed. California, Wadsworth Publishing Company, 1991, p. 284-296. 1967

BResser Pereira, Luiz Carlos. Administração pública gerencial: estratégia e estrutura para um novo Estado. Texto para Discussão no 9. Brasília, MARE/ENAP, 1996.

Uma reforma gerencial da Administração Pública no Brasil. Brasília, MARE, fevereiro de 1997, mimeo.

Downs, Anthony. The life cycle of bureaus (1967). In: Shafritz, Jay M. \& Hyde, Albert (ed.). Classics of Public Administration. 3 ed. California, Wadsworth Publishing Company, 1991, p. 305-318.

Evans, Peter. O Estado como problema e solução. Lua Nova. São Paulo, CEDEC, 28/ 29:107-156, 1993.

Flynn, Norman \& Strehl, Franz. Public sector management in Europe. Prentice Hall, Harvaster Wheatsheaf, 1996, p. 1-22.

Frederickson, H. George. Toward a New Public Administration. In: Shafritz, Jay M., \& Hyde, Albert (ed.). Classics of Public Administration. 3. ed. California, Wadsworth Publishing Company, 1991, p. 368-381, 1971.

Girglioli. Pier Paolo. Burocracia. In: Bobbio, Norberto et alii. Dicionário de Política. 7. ed. Brasília, UnB, v.1, 1995.

KASZNAR, Istvan K. A tipologia da motivação burocrática para administradores públicos de Marvick e os constructos de Downs, Gouldner, Tullock e outros. Revista de Administração Pública. Rio de Janeiro, FGV, 30(6):5-20, nov./dez. 1996.

Katz, Daniel \& Kahn, Robert L. Psicologia social das organizações. Trad. Auriphebo Simões. 3. ed. São Paulo, Atlas, 1987.

LANE, Jan Erik. The public sector: concepts, models and approaches. Sage, 1993, cap.2.

Machado de Assis, Joaquim Maria. A Semana: crônicas (1892-1893). Edição, introdução e notas de John Gledson. São Paulo, Hucitec, 1996.

Melo, Marcus André. Governance e reforma do Estado: o paradigma agente x principal. Revista do Serviço Público. Brasília, ENAP, 120(1): 67-82, jan./abr. 1996.

Melo, Marcus André \& Costa, Nilson do Rosário. A difusão das reformas neoliberais: análise estratégica, atores e agendas internacionais. In: ReIs, Elisa P.; ALMEIDA, Maria Hermínia T. de, FrY, Peter (org.). Pluralismo, Espaço Social e Pesquisa. São Paulo, Hucitec, 1996, p. 153-176.

Moe, Terry M. The positive theory of public bureaucracy. In: Mueller, D. Perspectives on Public Choice. Cambridge University Press, 1997, p. 455-480.

Moтta, Paulo Roberto. Avaliação na Administração Pública: eficiência, eficácia e efetividade. s.l., s.d., mimeo. 
PollitT, Christopher. Managerialism and the public services: cuts or cultural change in the 1990s? 2. ed. Oxford, Blackwell, 1993.

SALotto, Marinei Bareisys. A produtividade no setor público. Dissertação de Mestrado. São Paulo, EAESP/FGV, 1992.

SCHNEIDER, Ben Ross. A conexão da carreira: uma análise comparativa de preferências e insulamento burocrático. Revista do Serviço Público. Brasília, ENAP, 119(1):9-43, jan./abr. 1995.

Schwartzman, Simon. Desempenho e controle na reforma administrativa. Texto para Discussão n.8. Brasília, MARE/ENAP, 1996.

Sennett, Richard. O declínio do homem público: as tiranias da intimidade. Trad. Lygia Watanabe. São Paulo, Companhia das Letras, 1995.

Tojal, Flávio \& CARvalho, Wagner. Teoria e prática da burocracia estatal. Revista de Administração Pública. Rio de Janeiro, FGV, 31(1):50-68, jan./fev. 1997.

Toneto JR., Rudinei. Buchanan e a análise econômica da política. Lua Nova. São Paulo, CEDEC, 38:125-145, 1996.

WeBER, Max. Economia e sociedade: fundamentos da sociologia compreensiva. 3. ed. Brasília, UnB, 1994, v.1. 


\section{Burocracia, eficiência e modelos de gestão pública: um ensaio}

Este artigo apresenta diferentes visões sobre burocracia e eficiência, fazendo o contraponto com alguns modelos de gestão pública, tais como o tradicional ou ortodoxo, o liberal e o chamado empreendedorismo estatal. Discute o relacionamento entre burocracia e eficiência, com um exemplo extraído do gerencialismo britânico, orientador de reformas administrativas em diversos países. Elenca algumas questões recorrentes, que norteiam diversos modelos de gestão pública em sua busca por eficiência e que têm indiscutível importância no âmbito da administração pública.

\section{Burocracia, eficiencia y modelos de gestión pública: un ensayo \\ Cecília Vescovi de Aragão}

Este artículo presenta diferentes visiones sobre burocracia y eficiencia, haciendo un contrapunto con algunos modelos de gestión pública, tales como el tradicional u ortodoxo, el liberal y el llamado emprendedorismo estatal. Discute las relaciones entre burocracia y eficiencia, con un ejemplo sacado del modelo gerencial británico, orientador de reformas administrativas en diversos países. Expone una relación de cuestiones recurrentes, que orientan diversos modelos de gestión pública, en su búsqueda de eficiencia, y que tienen una importancia indiscutible en el ámbito de la administración pública.

\section{Bureaucracy, efficiency and public management models: an essay}

\section{Cecília Vescovi de Aragão}

This article sets forth different views on bureaucracy and efficiency and draws a comparison between certain public management models, such as the traditional or orthodox, the liberal model and the so called State entrepreneurship. The article further discusses the relation between bureaucracy and efficiency through an example drawn from the british experience in managerialism, a model that has guided administrative reforms in many countries. Some recurring issues that have spearheaded several models of public management in their pursuit of efficiency and that are indisputably relevant to public administration are also highlighted.

Mestre em administração pública pela EBAP/FGV e especialista em políticas públicas e gestão governamental, no Ministério da Fazenda 